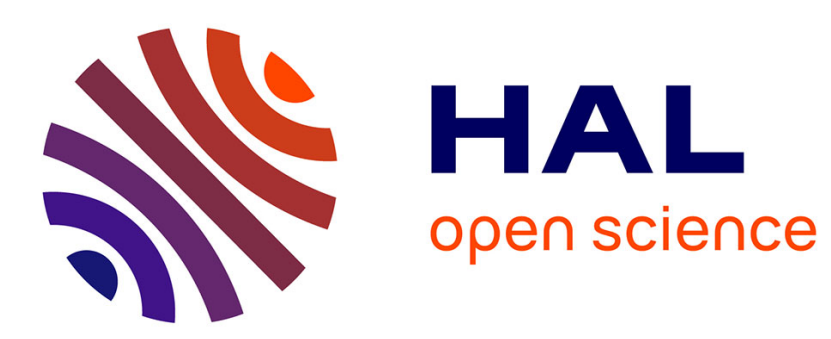

\title{
A STUDY OF THE INTERNAL FRICTION IN CONCENTRATED COPPER ALLOYS
}

\author{
Q. Kong, K. Lücke, G. Sokolowski
}

\section{To cite this version:}

Q. Kong, K. Lücke, G. Sokolowski. A STUDY OF THE INTERNAL FRICTION IN CONCENTRATED COPPER ALLOYS. Journal de Physique Colloques, 1981, 42 (C5), pp.C5-271-C5-276. 10.1051/jphyscol:1981539 . jpa-00221081

\section{HAL Id: jpa-00221081 https://hal.science/jpa-00221081}

Submitted on 1 Jan 1981

HAL is a multi-disciplinary open access archive for the deposit and dissemination of scientific research documents, whether they are published or not. The documents may come from teaching and research institutions in France or abroad, or from public or private research centers.
L'archive ouverte pluridisciplinaire HAL, est destinée au dépôt et à la diffusion de documents scientifiques de niveau recherche, publiés ou non, émanant des établissements d'enseignement et de recherche français ou étrangers, des laboratoires publics ou privés. 


\section{A STUDY OF THE INTERNAL FRICTION IN CONCENTRATED COPPER ALLOYS}

Q.P. Kong*, K. Lücke and G. Sokolowski

Institut für AlZgemeine Metalzkunde und Metalzphysik, RWTH Aachen, F.R.G.

Abstract.- In several $\mathrm{Cu}-\mathrm{A} 1$ and $\mathrm{Cu}-\mathrm{Zn}$ alloys damping peaks at about $200 \mathrm{~K}$ have been observed. The effects are due to interactions of dislocations with solute atoms. Possible mecharisms have been discussed.

1. Introduction. - Internal friction effects after cold-work have been studied extensively on pure metals and dilute alloys. However, they have very seldomly been extended to concentrated alloys. So Iseki et al /1/ investigated Cu-Al alloys and found a very high peak in CU15at\%AT alloys. In the present investigation the deformation and concentration dependences of this peak have been studied for CU-A1 alloys and also preliminary results for Cu-Zn alloys will be presented.

2. Experimental Procedure.- An automatic inverse torsion pendulum was used to measure decrement and shear modulus $G$ during linear heating and cooling at $1.6 \mathrm{~Hz}$. and an amplitude of $5 \times 10^{-5} / 2 /$. The samples had a diameter of $0.5 \mathrm{~mm}$ and a length of $15 \mathrm{~mm}$. The a.1 loys were prepared from $99.999 \%$ materials and the nominal contents are 2, 5, 10 and 15 atomic \% Al for $\mathrm{Cu}-\mathrm{A} 7$, and $2.5,5,10$ and $30 \mathrm{at} \% \mathrm{Zn}$ for $\mathrm{Cu}-\mathrm{Zn}$. In drawing the wires intermediate anneals at $500^{\circ} \mathrm{C}$ for 1.5 hours in vacuum (Cu-Al) or nitrogen atmosphere $(\mathrm{C} u-Z n)$ have been used at suitable diameters. Thus the final drawing down to $0,5 \mathrm{~mm}$ diameter at $300 \mathrm{~K}$ determined the deformation of the sample in reduction of area (RA). The time between the last drawing and the start of cooling down the pendulum cryostat was normally 1 hour.

3. Experimenta1 Resu1ts.- For a Cu15at\%A1 alloy in Fig. 1 decrement curves are given for different degrees of deformation. In all curves there is an amplitude-independent peak at about $200 \mathrm{~K}$, which first increases with deformation, reaches a maximum at $55.5 \% \mathrm{RA}$ and then decreases. Therefore the deformation of $55.5 \%$ RA has been chosen for the further investigations.

Fig. 2 shows the annealing behaviour of this peak in Cu15at\%A1 after $55.5 \%$ RA at $300 \mathrm{~K}$. The annealing temperatures given in Fig. 2 correspond to the maximum temperatures of successive linear heatings. At these temperatures the linear heating was reversed to linear cooling, during which the measurements given in Fig.2 were performed. The heating curves are omitted for clarity, but they reproduce the cooling curve of the same state of the sample. It can be seen, that the peak height decreases

\footnotetext{
*Q.P. Kong (C.P. Kung), as a guest from the Institute of Metal Research, Academia Sinica, Shenyang, China
} 


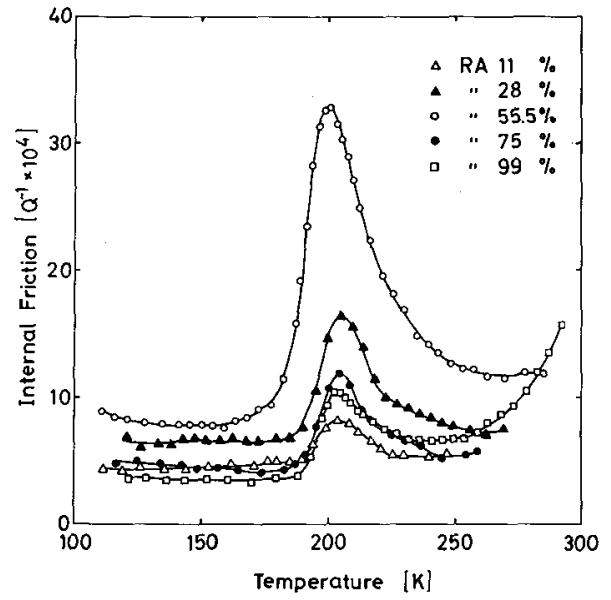

Fig.1 Internal friction of Cu15at\%A] for different degrees of deformation.

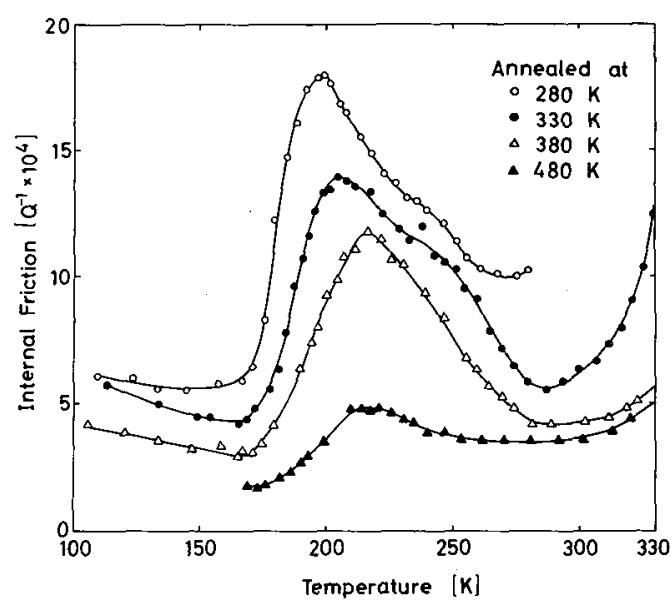

Fig. 2 Annealing behaviour of the internal friction peak in Cu15at\%Al.

and the peak temperature is shifted to higher values. The recovery of the peak just above room temperature corresponds to the observations that after a low temperature deformation there is a pinning stage at about $250 \mathrm{~K}$ followed by a slight pinning between 280 and $340 \mathrm{~K}$ and that a storage at room temperature for 1 day decreases the peak height. Therefore the time intervals between the last drawing of the sample and the cooling down of the pendulum was reduced to about 1 hour.

The internal friction curves of CU-AT alloys with different concentrations and the same deformation of $55.5 \%$ RA are depicted in Fig.3. It can be seen that the peak height increases strongly with concentration while the peak temperature is almost independent of concentration.

Fig. 4 gives similar curves for CU-Zn alloys after $55.5 \%$ RA. Also here a peak can

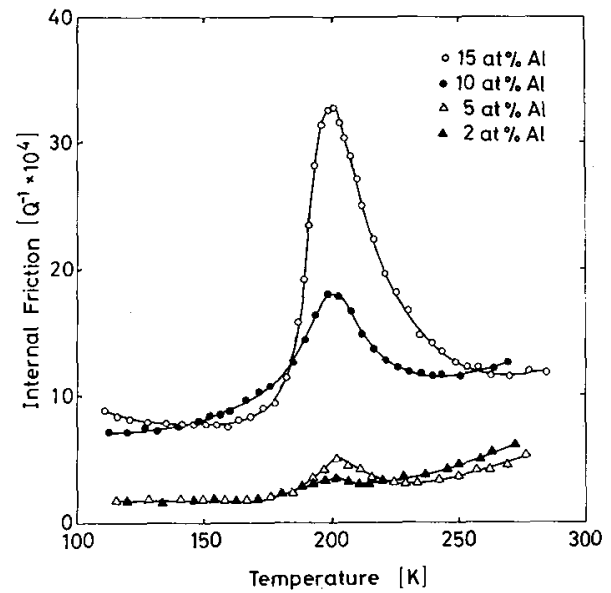

Fig. 3 Internal friction of CU-Al alloys with different concentrations after the same deformation. 


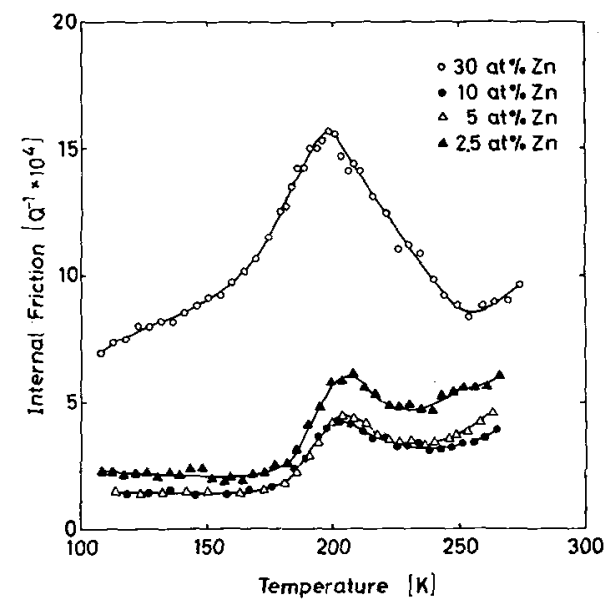

Fig. 4 Internal friction of $\mathrm{Cu}-\mathrm{Zn}$ a 71 oys with different concentrations after the same deformation.

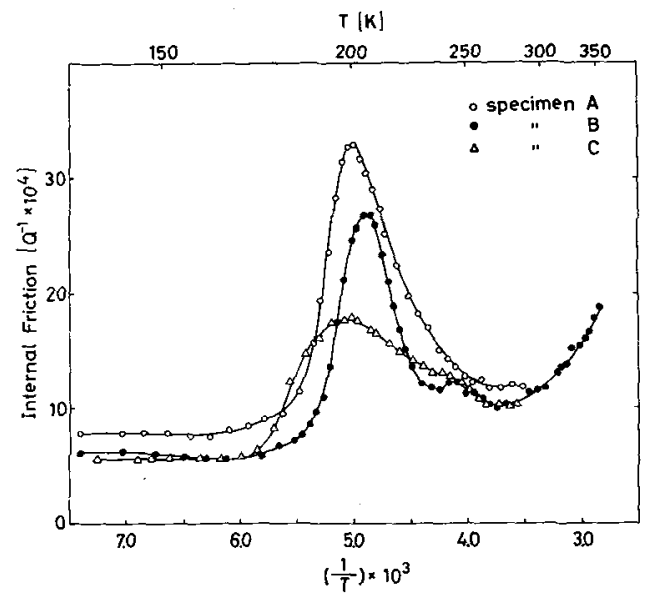

Fig. 5 Interna friction of different samples of Cu15at\%Al after the same deformation.

be found at about $200 \mathrm{~K}$. Its height is nearly independent of concentration for 2.5 , 5 and 10 at\% $\mathrm{Zn}$ and increases for 30 at\% $\mathrm{Zn}$, where it is still smaller than that in the Cui $5 a t \% A 1$ a $110 y$.

Fig. 5 demonstrates the reproducibility of the peak in Cu15at\%A7 after the same deformation of $55.5 \% \mathrm{RA}$ and pre-treatment. The height and shape differ and especially for sample $C$ the high temperature side of the peak is very flat. In two cases (samples $B$ and $C$ ) there is an additional small peak at about $235-240 \mathrm{~K}$ (see also Fig.2). In Fig. 6, where the square of the frequency $f$ being proportional to the shear modulus is plotted, the temperature dependence of modulus for the samples of Fig. 5 is given as an example.

Fig. 6 Shear modulus $\left(f^{2}\right)$ for the samples of Fig. 5

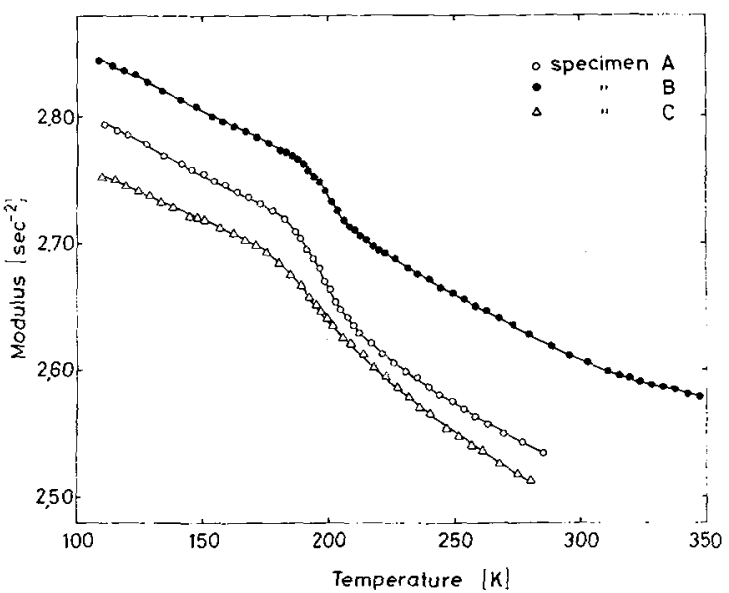


4. Discussion.- At present no quantitative model can definitely be assigned to the mechanism of the damping peak, only some points of view will be discussed:

1. Although the present alloy Cu15at\%Ai has the same A1-content as in /1/ and in both experiments practicaliy the same frequencies were used, in the present work the peak height is smaller by a factor 4 to 8 , the peak temperature is Tower by $30 \mathrm{k}$ and the peak width is larger by a factor of 2 . The reason for this differences is not known; they may be connected with the mode and amount of deformation which are not given in $/ 1 /$.

2. For a simple Debye peak the peak height $Q_{\max }^{-1}$ and the associated modulus defect $\Delta G / G$ are connected by

$$
2 \cdot Q_{\max }^{-1}=\alpha(\Delta G / G)
$$

where $\alpha=1$. After deducing a suitable background damping curve, for all peaks values $0.1 \leqq \alpha \leqq 0.25$ were obtained. This indicates a superposition of many relaxation processes.

3. For a single activation process the activation energy $H$ can be obtained as $/ 3 /$

$$
H=\frac{\pi}{2} \cdot \frac{k}{A} \cdot \frac{\Delta G}{G}
$$

where $k$ is the Boltzmann constant and

$$
A=\int_{0}^{\infty} Q^{-1} d\left(\frac{1}{T}\right)=\frac{\pi}{2} \cdot \frac{k}{H} \cdot \Delta_{R}
$$

the area of the peak in the plots $Q^{-1}$ vs. $1 / T$ (Fig.5) and $\Delta_{R}$ the relaxation strength. In the present case of superpositions of relaxation processes Eq. (3) gives an effective activation energy $\mathrm{H}_{\text {eff }}$ which should have the right magnitude if the distribution in $H$ is not too broad. The peaks of Fig. 5 lead to $H_{\text {eff }}=2 \mathrm{eV}$, which is close to the value determined from the frequency shift of the peaks in $/ 1 /$.

4. Although this value $H_{\text {eff }}=2 \mathrm{eV}$ is very close to the migration energy of $\mathrm{Al}$ in Cu15at\%A] $/ 4 /$, it can here have no real physical meaning. If one sets for the peak $\omega \tau=1$ with

$$
\frac{1}{\tau}=\frac{1}{\tau_{0}} \exp (-H / k T)
$$

it should lead to the completely unreasonable value $\tau_{0}=6 \times 10^{-52} \mathrm{sec}$. An interpretation of these high effective activation energies is given by Lücke et al $/ 5 /$ and Koiwa $/ 6 /$ by assuming that in the temperature range of the peak processes occur changing $\Delta_{R}$ or the simple temperature dependence of $\tau$ given by Eq. (4). Examples for such processes are the evaporation of a Cottrell atmosphere or a disordering of a 
Snoek or Zener atmosphere near the dislocation during heating, if the damping mechanism is connected e.g. with diffusion or reorientation drag, respectively.

5. For Cu15at\%Al it could be shown that the peak height first increases with the degree of deformation, i.e. dislocations should be involved in the relaxation process. The decrease at higher deformations seems to indicate, that due to the increased interactions between the dislocations the relaxation strength of the process is decreased. Since the peak height increases with the concentration (especially in the CU-Al alloys) the relaxation process should be associated with the interactions between dislocations and the solute atoms.

6. At low deformations two types of restoring forces of the dislocations may be considered: The restoring force due to the line tension gives a spring constant /7/

$$
K_{C}=12 C / L^{2}=6 G b^{2} / L^{2}
$$

If the dislocations are split into partials as in alloys with low stacking fault energy $\gamma$, the restoring force should be determined by the interactions between the partials. With the repulsive force $/ 8 /$

$$
F_{1}=G b^{2} / 24 \pi \cdot r=a /\left(r_{0}+x\right) \sim \frac{a}{r_{0}}\left(1-\frac{x}{r_{0}}\right)
$$

between the partials in distance $r$ and the equilibrium distance $r_{0}=a / \gamma$ the balance of forces is

$$
F_{\text {ext }}=F_{1}-\gamma=\frac{a}{r_{0}}\left(1-\frac{x}{r_{0}}\right)-\gamma=-\frac{y^{2}}{a} \cdot x
$$

and gives a spring constant

$$
K_{\gamma}=\frac{\gamma^{2}}{a}=\gamma^{2} \cdot 24 \pi / G b^{2}
$$

Using the value $\gamma / G=1.1 \times 10^{-12} \mathrm{~m} / 9 /$ it follows from Eq. (4) and (7) that $\mathrm{K}_{\gamma}$ corresponds to an effective loop length

$$
L_{\text {eff }}=G b^{2} / \gamma \cdot 2 \sqrt{\pi}=2 \cdot 10^{-6} \mathrm{~cm}
$$

This is of the same order of magnitude than the loop length $L$ in $K_{C}$ for heavily deformed samples, so that it is difficult to distinguish between the restoring mechanisms by the absolute value of the spring constant. However, the increase of the relaxation strength $\Delta_{R} \approx \Lambda G b^{2} / K / 7 /$ with concentration as in the CU-AT alloys speaks in favour of the stacking fault mechanism, since the increase of concentration decreases $\gamma$ and thus also $K_{\gamma}$ and increases $\Delta_{R}$. To explain this by the loop length mechanism 
would require an increase of $L$ with concentration which is not plausible.

7. The annealing between 330 and $480 \mathrm{~K}$ decreases the peak height by $80 \%$ ind $i-$ cating a corresponding reduction of $\Delta_{R}=\Lambda G b^{2} / K$, while the modulus curve as a whole is increased by $3.6 \%$. Both could be explained either by a decrease in L, i.e. pinning for the case that we have string vibrations or a decrease in $\Lambda$ for the case that we have stacking fault vibrations. The increase in peak temperature by $19 \mathrm{~K}$ during recovery might also indicate that the low temperature processes recover faster than those at high temperatures.

\section{References}

11/ M. Iseki, M. Koiwa, M. Hirabayashi, in "Internal Friction and UTtrasonic Attenuation in Solids", Ed. R.R. Hasiguti, N. Mikoshiba, University of Tokyo Press, 1977 , p. 659

12/ A. Schne11, G. Sokolowski, H. Brumme, J. Physics E9, 833 (1976)

/3/ Q.P. Kong (C.P. Kung), C.C. Chang, Acta physica Sinica 24, 168 (1975)

/4/ Metals Reference Book, Vol.II, Ed. 3, Butterworths, London (1962) p. 591

/5/ K. Lücke, A. Schnell, G. Sokolowski, see Ref. 1, p. 99

16/ M Koiwa, see Ref. 1, p. 664

/7/ D. Lenz, K. Lücke, in "Internal Friction and U1trasonic Attenuation in Crystalline Solids", Vol.II, Ed. D. Lenz, K. Lücke, Springer-Verlag, Berlin, 1975, p. 48

18/ A.H. Cottrell, Dislocations and Plastic Flow in Crystals, Oxford, At the Clarendon Press, 1953, p. 74

19/ H.P. Karnthaler, B. Schiirgel, in "Strength of Metals and Alloys", Vol.I; Ed. P. Haasen, V. Gerold, G. Kostorz, Pergamon Press, 1979, p. 209 